\title{
The message in the box: how exposure to money affects charitable giving
}

\author{
Ahmet Ekici $^{1}$ • Aminreza Shiri ${ }^{1}$ \\ Published online: 22 April 2018 \\ (C) Springer Science+Business Media, LLC, part of Springer Nature 2018
}

\begin{abstract}
Does donation box transparency matter in regard to donation behavior? The purpose of this research is to test the effect of donation box transparency on potential donors' charitable behavior. In a series of experimental studies, including a field experiment, data were collected on willingness to donate and donation amount in three treatments: a wooden donation box (opaque condition), transparent donation box containing very little money, and transparent box almost full of money. Participants in the transparent box treatment were both less willing to donate money and they donated less money compared to subjects in the opaque box treatment. Moreover, data was collected to demonstrate that participants in the transparent box conditions experienced a heightened state of self-sufficiency due to the effect of money exposure. Implications are discussed for theory development and future research avenues and in terms of practical considerations for charity organizations.
\end{abstract}

Keywords Donation Prosocial behavior tendency · Money exposure - Self-sufficiency · Charitable giving

\section{Introduction}

If recently, you have been in an airport, shopping mall, or any other retail space, you are likely to have encountered donation boxes constructed from a transparent material such as glass or plastic. The logic underlying such widespread choice of transparent boxes may be an implicit belief that showing money left by others may inspire other donors to follow suit. "Seed money" might even be pre-placed to encourage donations, similar to

Ahmet Ekici

ekici@bilkent.edu.tr

Aminreza Shiri

aminreza.shiri@bilkent.edu.tr

1 Bilkent University, Ankara, Turkey 
the practice frequently observed for tip jars placed on counters or open guitar cases in front of street musicians. But are charities - from the most recognized to the least recognized - truly benefiting from using transparent boxes?

There is a large body of research on charitable giving behavior. In general, research on charitable giving has aimed to answer questions such as the following: (1) what drives charitable giving? (e.g., Aaker and Akutsu 2009; Wang et al. 2015); (2) what are the physical and mental benefits of charitable giving for donors? (e.g., Aknin et al. 2013; Whillans et al. 2016); and (3) how charitable giving behavior can be increased? (e.g., Anik et al. 2014; Guèguen 2013).

The question of how charitable giving behavior can be increased is typically an implication of the preceding research streams. Of particular relevance to the current investigation is the stream of research in the donation domain that examines the effects of priming in the form of exposure to money. Money exposure studies find that people primed with money (versus a neutral prime) become more self-centered (e.g., Gasiorowska and Helka 2012). The vast majority of these studies applied conceptual money exposure methods such as phrase descrambling and measured dependent variables such as speediness to complete a task, intention to cooperate with instrumental partner, and feeling strong. For a list of studies examining the effects of exposure to money to this date, please see Vohs (2015). While the effect of money priming on behavior has been established by many studies conducted to date, there are cases that these effects were not present. For example, in a series of studies, Caruso et al. (2017) found no main effect of money priming on dependent measures. While the study by Caruso et al. (2017) may not be the last word on money priming, such disparate findings calls for a re-examination of the topic, and in fact, this is one of the main motives behind conducting the present research. We do so by examining the effect of donation box transparency on people's willingness to donate and the amount they donate, which extends the context in which precedent exposure to money studies have been conducted. We also explore possible mechanisms behind any observed effects.

\section{Background and conceptual development}

One may ask, what could possibly go wrong when charities expose donors to money using transparent boxes? To answer this question, it is essential to understand how exposure to money may prompt temporary changes in psychological states and consequent changes in behavior. When charitable organizations use transparent boxes to collect money, they simultaneously provide subtle informational cues to their prospective donors. Exposing people to money is a form of perceptual priming, which relies on implicit human memory (Tulving and Schacter 1990) and unconsciously influences present behavior (Schacter and Buckner 1998). As the concept of money is highly accessible and strongly motivational (Vohs 2015), its unintentional priming may represent a strong influence on donation behavior.

When people are exposed to money or reminded of it-whether it is real money, visual images, or symbolic representations (words, thoughts) - they may be subject to temporary changes in their psychological states. In line with this understanding, Vohs et al. (2006) predicted and found that people exposed to 
money evinced a higher state of self-sufficiency, "an emphasis on behaviors of one's own choosing accomplished without active involvement of others" (p. 209). Vohs et al. (2006) theorize that "reminders of money would lead to changes in behavior that suggest a feeling of self-sufficiency" (p. 1154).

Three major outcomes of being in a self-sufficient state are that people become less responsive to others' needs, seek to be independent from others, and do not like to have people dependent on them (Vohs et al. 2006). In a series of nine experiments, Vohs et al. discovered that when primed with the concept of money, people tended to be less helpful, engage in fewer voluntary activities, and prefer individualism over communality. In reviewing 165 money exposure studies from 18 countries, Vohs (2015) summarizes the effect of exposure to money as follows: "People reminded of money, compared to other concepts, are unhelpful, stingy, and disinterested in social contact." (p. 2). These behavioral changes, caused by exposure to money, are not limited to people in a specific geographic location or age group; similar effects are found among children, college students, and business managers around the world from Europe to North America, and Asia (Vohs 2015; Zhou et al. 2009).

While the abovementioned studies mainly examined the effects of exposure to money through the concept of money (i.e., story-telling, screen saver images, phrase unscramble), there are, additionally, studies that have used real money to prime subjects in experiments. In an attempt to study exposure to money effects on helping behavior in a natural setting, participants were approached before and after using ATM machines (Guèguen and Jacob 2013). The experimenter asked for help from some people before they used the ATM and from others after they used it. Results showed that participants who were asked for help after they used the ATM machine were much less willing to help the experimenter compared to those who were asked before they used it.

Similarly, in the present research, we are interested in the fact that exposure to money reminds people of money as a tool with which they can achieve their goals and sets people in a market exchange orientation (Lea and Webley 2006). This in return puts people in a self-sufficient state (Vohs et al. 2008), where they potentially prefer individualism over communality. The notion of money has become remarkably accessible as it regularly passed from one person's hands to the others', or through their eyesight and minds - that is, frequent for a considerable number of them. Importantly, in the cases that the content of prime is accessible enough, indirect hints evocative of it may be enough to influence behavior (Higgins and Brendl 1995).

Although the literature on exposure to money covers a wide range of related issues, charitable giving behavior has not received as much attention. The traditional and common way of collecting monetary donations by donation boxes appears to be a relevant issue to be studied in terms of the effects of exposure to money and, more importantly, offers practical implications to charitable organizations. Building upon the works of Vohs et al. (2006) and Lea and Webley (2006) and in light of the preceding discussion, we propose the following hypotheses:

H1A: Opaque donation boxes will induce greater donation willingness than transparent boxes.

H1B: Opaque donation boxes will induce higher amount of donation than transparent boxes. 
In the hypotheses $\mathrm{H} 1 \mathrm{~A}$ and $\mathrm{H} 1 \mathrm{~B}$, we expect that participants in the transparent conditions behave differently than those in the opaque condition. We predict that participants in the transparent donation box conditions (almost empty and almost full) will not be triggered to donate and even when they do decide to donate, they would be donating lesser amounts compared to those participants in the opaque condition. This prediction only tests the immediate action that needs to be taken by participants in order for us to examine the validity of our hypotheses. Therefore, to examine the theoretical framework of our study, we measure the future commitment (volunteering activities) of participants to a charitable organization, which brings us to our second hypothesis:

H2: Transparent donation boxes will induce lower likelihood to volunteer than opaque boxes.

We predict that people in the transparent conditions, as a result of being exposed to money, will be less likely to volunteer to help a charity activity in future. This prediction is relative in that it is compared to the opaque condition. In transparent conditions, the exposure to money takes place whereas that is not the case in the opaque condition. This brings us to the last hypothesis of our paper which outlines the reason behind our prediction in the earlier two hypotheses:

H3: Transparent donation boxes will put people in a self-sufficient psychological mode.

The exposure of money makes people to think more about their own needs and themselves. This state of the mind - self-sufficiency - is potentially caused by the transparent donation boxes as they expose donors to money regardless of the volume. Thus, we hypothesize that when participants are faced with transparent boxes, relative to participants in the opaque condition, they will present thoughts and behavior resembling to that of people who are in the self-sufficient mode, leading to a lesser willingness to partake in the donation. Through two lab experiments and a large-scale field experiment, we tested these hypotheses.

\section{Study 1}

Our motivation for the study 1 was, first, to determine whether donors found one type of donation box more attractive than the other (transparent versus non-transparent), in order to rule out alternative explanations for any observed effects of box transparency on donation behavior. Second, we wanted to determine whether donation box type influenced how donors perceived the charity organization (UNICEF, in our study); according to Meijer (2009), willingness to donate and the donation amount can be influenced by how donors perceive the charity organization in terms of reliability, trustworthiness, and service importance. Third, we had to make sure that the perceived "secureness" of the donation box against potential theft is not influenced by the transparency of the box, which may in return influence donation behavior. Fourth, based on our prediction, a completely empty transparent box should be very similar to opaque box in the produced effect, as there is no money to cause the money priming. 
With the same logic, an opaque box with a picture of money attached to it should produce similar effects to those by transparent boxes with money visible inside.

In total, 206 students (49\% female; $M_{\text {age }}=21.85, \mathrm{SD}=2.1$ ) from two universities located in Ankara (capital of Turkey) participated in the pre-test study. The results revealed that donation box material did not influence how individuals perceived the charity organization. In addition, participants did not find one box design more attractive, more likable, and or more secure over the others (all $F \mathrm{~s}<1.0$ ). These results help rule out alternative explanations for any possible relationships revealed in the main experiment (study 2). More importantly, there was a main effect of money presence in the pictures (inside the transparent boxes and on the opaque box) on the willingness to donate $(F(4,201)=5.84, p<0.001)$. We found that participants in opaque box condition and the transparent box with no money scored significantly higher in the willingness to donate measure, compared to the other three conditions (transparent almost empty, transparent almost full, and opaque with picture on money printed on). There was not a significant difference between opaque box condition and transparent completely empty in terms of the willingness to donate $\left(M_{\text {opaque }}=3.26, \mathrm{SD}=1.27 ; M_{\text {transparent-empty }}=\right.$ $3.64, \mathrm{SD}=1.35 ; t(72)=1.22, p=0.22)$. This is in fact parallel to our hypothesis, stating that the presence of money in the transparent donation boxes will induce lower donation willingness. Referring to the results elicited from study 1, we will be using the three main conditions in study 2 and study 3 (the field experiment): opaque box, transparent almost empty, and transparent almost full. Tables 1 and 2 provide detailed information about the study 1 procedures and the results.

\section{Study 2}

The lab experiment was designed to test the effects of exposure to money on participants' willingness to donate and the mechanism (i.e., the self-sufficiency hypothesis) behind the results in the experiment.

\subsection{Experimental procedures}

In total, 186 students $\left(55 \%\right.$ female; $\left.M_{\text {age }}=22.4, \mathrm{SD}=1.4\right)$ from two universities located in Ankara and Istanbul (largest city in Turkey) but using a new pool of participants who did not take part in the Study 1 participated in this experiment. Experimenters who were blind to research hypotheses randomly assigned participants to one of the three conditions: opaque box $(N=61)$, transparent box with almost no money $(N=59)$, or transparent box almost full of money $(N=65)$. The questionnaires for each group were identical except for the donation box photo used in each of the three experiment conditions. At the top of the first page, participants read the following scenario which attempted to create equivalence in the amount of money and the social situation faced by each participant:

You have just eaten at the restaurant on campus and paid with a 50TL note you had in your pocket. You bought the lunch for 11TL, so now you have 39TL left in your pocket. You are on your way to class alone, and you pass by the charity box (pictured below) designed to collect money for UNICEF (United Nations 
Table 1 Experimental procedures of study 1

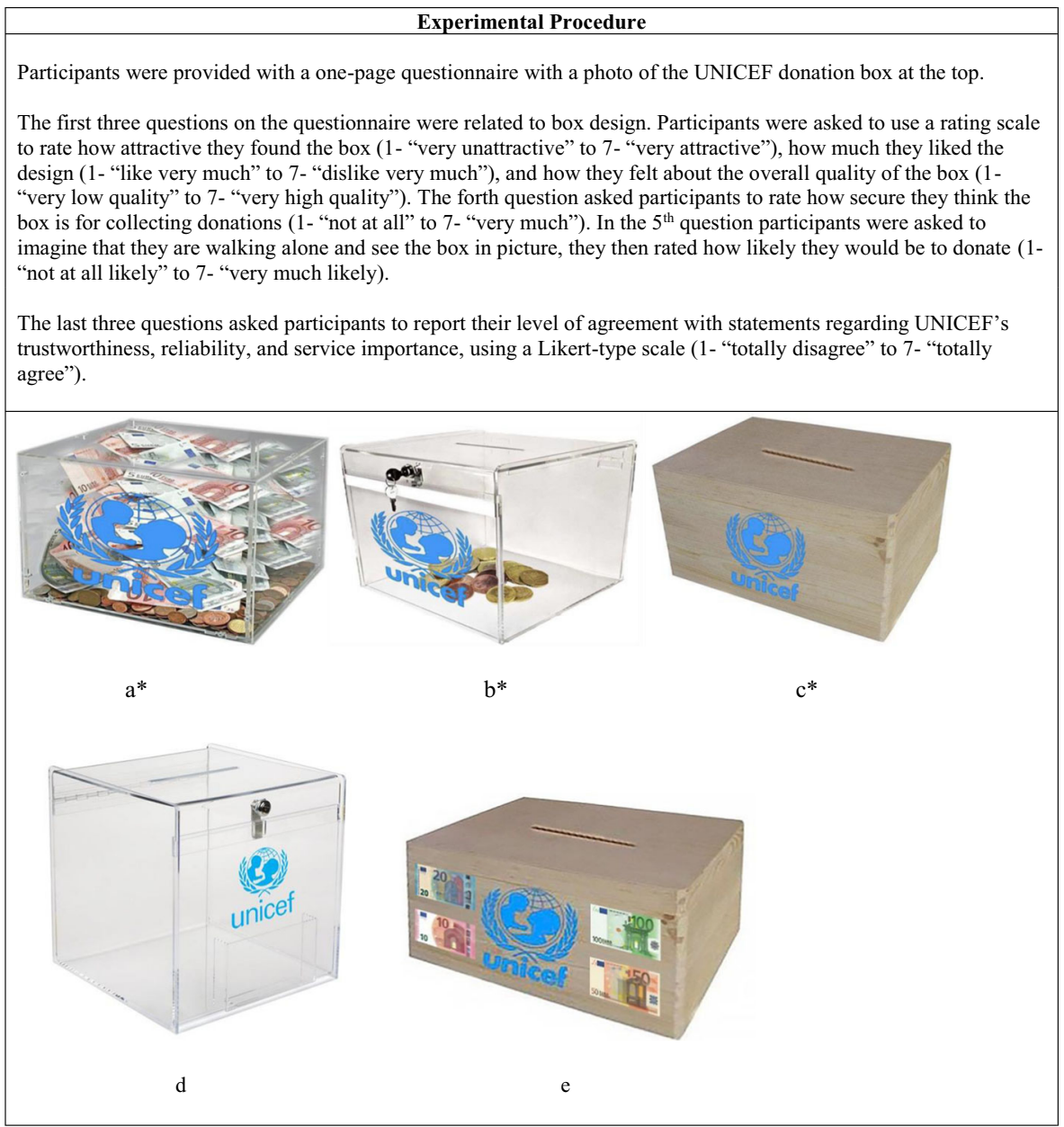

*Pictures of boxes a, b, and c were also used in study 2

International Children's Fund). UNICEF provides long-term humanitarian and developmental assistance to children and mothers in developing countries.

The currency used in the study was the Turkish Lira, and 1 US dollar was equivalent to three Turkish Liras. The photo of the donation box was printed under the scenario text (please see Table 1 for donation box photos). On the second page of the questionnaire, participants were asked to report their willingness to donate money (H1A) on a scale of 1 to 5 (1- "very unlikely" to 5- "very likely") and how much of the money left in their pocket (39 as in the scenario) they would be willing to donate (H1B). Afterward, they were asked to respond to a two-item Likert-type scale to measure selfsufficiency (H3). The items were designed to ascertain whether exposure to money produced the effects suggested by Vohs et al. (2006) — enhancing individualism and diminishing communal feelings, the subject of $\mathrm{H} 3$. The two items used were as follows: 
Table 2 Means and standard deviations for the dependent measurements in the study 1

\begin{tabular}{|c|c|c|c|c|c|}
\hline \multirow[b]{2}{*}{ Dependent Variables } & \multicolumn{5}{|c|}{ Experimental Condition } \\
\hline & $\sqrt{3}+r^{2}$ & $\frac{\infty}{(5)}$ & & $1 i^{8}$ & Ang $(3)$ : \\
\hline $\begin{array}{l}\text { Likability and overall } \\
\text { design of the donation } \\
\text { box }\end{array}$ & $3.34(0.94)$ & $3.55(1.02)$ & $3.43(0.72)$ & $3.39(0.77)$ & $3.49(1.04)$ \\
\hline $\begin{array}{l}\text { Perceived secureness of } \\
\text { the donation box }\end{array}$ & $2.46(1.45)$ & $3.05(1.59)$ & $2.97(1.44)$ & $3.22(1.46)$ & $3.34(1.78)$ \\
\hline Likelihood of donation & $2.70(1.6)$ & $2.86(1.44)$ & $3.26(1.27)$ & $3.64(1.35)$ & $2.22(1.23)$ \\
\hline $\begin{array}{l}\text { Trustworthiness, } \\
\text { reliability, and service } \\
\text { importance of UNICEF } \\
\text { (charity organization } \\
\text { used on the boxes) }\end{array}$ & $3.96(1.50)$ & $4.75(1.32)$ & $4.2(1.29)$ & $4.54(1.46)$ & $4.15(1.51)$ \\
\hline
\end{tabular}

"Right now I feel like I would prefer to be independent from others" and "At this moment I feel like I would prefer people to be independent from me" on a scale ranging from 1 to 5 (1- "completely disagree" to 5-“completely agree"). The items were found to be internally consistent (Cronbach's $\alpha=0.88$ ) and were summed to form the self-sufficiency measure.

To further investigate whether donation box transparency may affect helping behavior of participants (H2), the final question asked them to provide their email addresses to be contacted for participation (administration helps) in a fundraising campaign on their university campus. They were presented with the following text:

As part of an effort to help UNICEF, there will be a fundraising campaign to be held in [University Name] campus. Would you like to help this fundraising campaign? (Yes/No)

If your answer to the above question is yes, please provide us with your email address so that we can contact you to provide details about further steps.

\subsection{Results}

\subsubsection{Willingness to donate and donation amount}

We separately submitted donation willingness $(F(2,182)=7.73, p<0.001)$ and donation amount $(F(2,182)=49.44, p<0.001)$ to a single factor ANOVA test. In line with our prediction (H1A), willingness to donate was significantly higher among participants in the opaque condition than transparent almost-full condition $\left(M_{\text {opaque }}=3.52\right.$, 
$\left.\mathrm{SD}=1.36 ; M_{\text {transparent-full }}=2.87, \mathrm{SD}=1.12 ; t(124)=2.93, p<0.01, d=0.52\right)$ or in the transparent almost-empty condition $\left(M_{\text {opaque }}=3.52, \mathrm{SD}=1.36 ; M_{\text {transparent-almost empty }}=\right.$ $2.21, \mathrm{SD}=0.97 ; t(118)=6.06, p<0.01, d=1.11)$. Additionally, as predicted in H1B, hypothetical donation amount (in Turkish Lira) was significantly higher among participants in the opaque condition than transparent almost-full condition $\left(M_{\text {opaque }}=7.92\right.$, $\left.\mathrm{SD}=2.43 ; M_{\text {transparent-full }}=4.46, \mathrm{SD}=2.05 ; t(118)=9.23, p<0.01, d=1.54\right)$ or in the transparent almost-empty condition $\left(M_{\text {opaque }}=7.92, \mathrm{SD}=2.43 ; M_{\text {transparent-almost empty }}=\right.$ $4.10, \mathrm{SD}=1.83 ; t(124)=9.93, p<0.01, d=1.78)$. There was no difference in willingness to donate and hypothetical donation amount between transparent almost-full condition and transparent almost-empty condition $(p>0.5)$.

\subsubsection{Donation box transparency and self-sufficiency}

$\mathrm{H} 3$ predicted that transparent donation boxes containing visible currency would expose donors to money, heightening their self-sufficiency. There was a significant difference in participants' self-sufficiency across the three experimental conditions $(F(2,182)=$ $31.39, p<0.001)$. Participants in the opaque box condition were significantly less selfsufficient than participants in the transparent almost-empty condition $\left(M_{\text {opaque }}=3.16\right.$, $\mathrm{SD}=1.13 ; M_{\text {transparent-almost empty }}=4.33, \mathrm{SD}=1.01 ; t(119)=7.13, p<0.001, d=-$ $1.01)$ and participants in the transparent almost-full condition $\left(M_{\text {opaque }}=3.16, \mathrm{SD}=\right.$ $\left.1.13 ; M_{\text {transparent-full }}=4.67, \mathrm{SD}=1.22 ; t(125)=9.94, p<0.001, d=-1.28\right)$. Additionally, the two transparent conditions did not differ in terms of self-sufficiency $(p>0.5)$. Participants in the transparent box conditions (vs. the opaque box condition) reported heightened desire to be independent from others and to have others not be dependent on them.

To examine the mediating role of self-sufficiency on the relationship between exposure to prior donation and helping behavior, we conducted a mediation analysis using the Hayes PROCESS macro (opaque box condition coded with 0 and transparent condition coded with 1). This model supported mediation (see Figs. 1 and 2) by demonstrating that compared to transparent-empty condition, participants in opaque condition scored lower on self-sufficiency scale $(B=1.74, t=8.61, p<0.001)$, and lower self-sufficiency was associated with greater willingness to donate $(B=1.11, t=$ $4.01, p<0.001)$. Furthermore, compared to transparent-full condition, participants in opaque condition scored lower on self-sufficiency scale $(B=1.68, t=8.82, p<0.001)$, and lower self-sufficiency was associated with greater willingness to participate in the
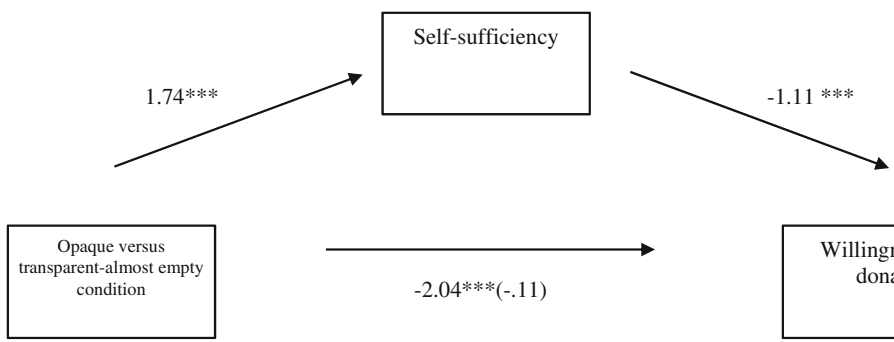

Willingness to donate

Fig. 1 The mediating role of self-sufficiency on the relationship between helping behavior and money exposure. The unstandardized beta is represented. $* * * p<0.001$ 


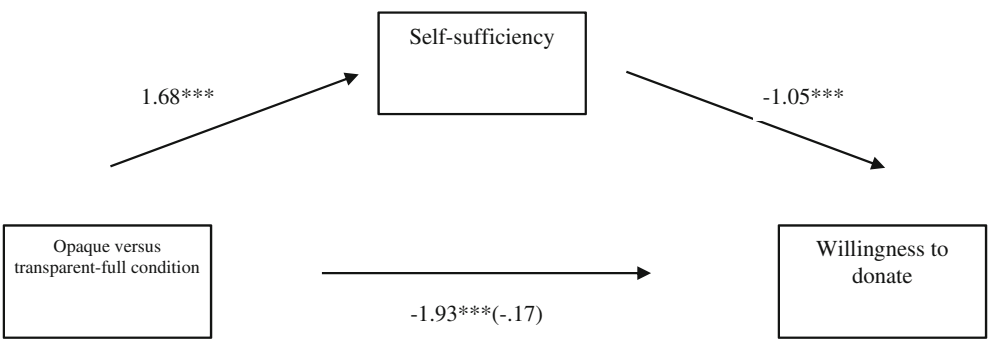

Fig. 2 The mediating role of self-sufficiency on the relationship between helping behavior and money exposure. The unstandardized beta is represented. $* * * p<0.001$

fundraising campaign $(B=1.05, t=3.57, p<0.001)$. Unfortunately, however, the mediation analysis for the amount of donation did not support a significant indirect path $(p>0.05)$. We believe one reason that we could not observe a significant path for amount of donation amount is that the donation amount was hypothetical and not from participants personal fund.

These results show that donation box transparency, when money is visible or not, significantly affects participants' self-sufficiency. A correlation analysis was conducted to examine the relationship between willingness to donate and self-sufficiency, which further validated the previous results: the self-sufficiency scale is negatively correlated with the willingness to donate $(r=-0.394, p<0.001)$.

\subsubsection{Helping behavior}

One of the outcomes of being in a heightened state of self-sufficiency is that people are less willing to help others (Vohs et al. 2006). To examine whether donation box transparency (i.e., the effect of money visibility) affects helping behavior other than donations, participants were asked to provide their email addresses if they wish to volunteer to help with a fundraising campaign on campus. The number of participants who reported they are willing to participate in the activity was the dependent measure. We compared the percentage of people who provided their email address across all three experimental conditions and found that participants exposed to the opaque donation box were significantly more likely to participate in the fundraising campaign than participants in transparent almost-empty condition $\left(P_{\text {opaque }}=77 \%, P_{\text {transparent-almost }}\right.$ empty $\left.=39 \% ; \chi^{2}=17.88, p<0.001\right)$ and almost-full condition $\left(P_{\text {opaque }}=77 \%\right.$, $\left.P_{\text {transparent-full }}=46 \% ; \chi^{2}=12.64, p<0.001\right)$.

Study 2 provided support for our prediction that transparent donation boxes with visible currency can trigger a heightened state of self-sufficiency. Participants in transparent box conditions reported they preferred to be independent from others and not to have others dependent on them. The level of money in the transparent boxes (almost full versus almost empty) did not show a significant effect on self-sufficiency, which is consistent with the literature on exposure to money suggesting that even a small amount of money may produce effects similar to larger amounts. Analogous effects were observed when participants were asked if they are willing to participate in a fundraising campaign on their campus. Those in transparent box conditions (regardless of level of money) were significantly less willing to volunteer compared to those in the opaque box condition. 


\section{Study 3: field experiment}

As consequential choices improve external validity of research findings, we conduct a field experiment to investigate whether the observed effects of donation box transparency on donations will materialize when people are asked to donate their own money in a field setting, providing test of H1B.

\subsection{Experimental procedures}

The experiment employed a between-subjects design, with box transparency and level of money manipulated as three conditions. This field study took place at the library of a well-known university located in Tehran (the capital of Iran) in single-occupancy study rooms. The charity used in the study was again UNICEF. Posters containing information about UNICEF were posted on the walls of 16 study rooms where donation boxes were placed. During the 1-week (6 days) experiment period, 578 students visited these study rooms; each student was allowed to use the room for one session in a week with a maximum of $2 \mathrm{~h}$ allowed in each room. This restriction on the number of sessions a student could use the study rooms helped us ensure that no student participated more than once in the experiment. The conditions in the study rooms were the same for a day and then changed the day after (i.e., on Monday, all boxes were opaque, on Tuesdays, all boxes were transparent almost empty, and on Wednesday, all boxes were transparent almost full).

Moreover, a research assistant who was blind to the hypotheses of our study approached students exiting the study room. The assistant asked students if they are willing to participate in a voluntary campaign (administrative helps for a charity of choice of the student) to be held on university campus, and if they agreed they would provide their email address (dependent variable) for further communications. After students left the study rooms area of the library, the same assistant examined the amount of money in the donation box to see whether the person has donated or not and recorded the amount of donated money. This was possible because we exactly knew the amount of seed money we placed in the transparent boxes and for the opaque box there was no money left in the box.

\subsection{Results}

We compared the percentage of people who donated money with the percentage of those who did not across the transparent and opaque conditions and we found that, consistent with our prediction, people in the opaque box condition were significantly more willing to donate money than participants in transparent almost-empty condition $\left(P_{\text {opaque }}=32 \%, P_{\text {transparent-almost empty }}=16 \% ; \chi^{2}=12.93, p<0.01\right)$ and participants in the transparent almost-full condition $\left(P_{\text {opaque }}=32 \%, P_{\text {transparent-full }}=20 \% ; \chi^{2}=6.88\right.$, $p<0.01)$. As for donation amount, there was a significant difference in the amount participants donated across the three experimental conditions $(F(2,128)=4.68, p=$ $0.011)$. Participants in the opaque box condition significantly donated more money than participants in the transparent almost-empty condition $\left(M_{\text {opaque }}=2.05, \mathrm{SD}=0.44\right.$; $\left.M_{\text {transparent-almost empty }}=1.78, \mathrm{SD}=0.51 ; t(90)=2.66, p<0.01, d=0.56\right)$ and participants in the transparent almost-full condition $\left(M_{\text {opaque }}=2.05, \mathrm{SD}=0.44 ; M_{\text {transparent-full }}\right.$ 
$=1.85, \mathrm{SD}=0.38 ; t(96)=2.32, p=0.02, d=0.49)$. Additionally, the two transparent conditions did not differ in terms of donation amount $(p>0.5)$.

Importantly, we found that compared to participants in the opaque condition, those in transparent almost-full condition $\left(P_{\text {opaque }}=40 \%, P_{\text {transparent-full }}=11 \% ; \chi^{2}=20.78\right.$, $p<0.01)$ and transparent almost-empty condition $\left(P_{\text {opaque }}=40 \%, P_{\text {transparent-almost empty }}\right.$ $\left.=16 \% ; \chi^{2}=16.88, p<0.01\right)$ were significantly less willing to participate in the volunteering activity which was measured by collecting their email addresses if they wished to participate (Table 3 ).

These results were parallel to those observed in study 2. Participants were not only more willing to donate in the opaque box condition, but they also donated the highest amount of money to the charity. Interestingly, subjects presented with the transparent box with only a few coins and bills in it behaved very similarly to participants presented with the transparent box full of money. Neither willingness nor donation amount were significantly different between the two groups, which suggests, aligned with the money-priming theory, that even a very small amount of money (in the form of a few coins) can produce money exposure effects and put people in a self-sufficient state.

\section{General discussion}

The effect of donation box transparency on donations has not been explored in past research, so the current investigation sought to address this void with a series of studies, both in the laboratory and in the field. Overall, we find evidence for the effect of donation box transparency on donor behavior. The study suggests that donation boxes made of non-transparent material (e.g., wooden boxes) receive more donations - both in terms of amount and frequency - compared to donation boxes made of transparent material (e.g., glass) with some money in them. We believe that self-sufficiency through money exposure explains these results, where exposure to money causes people to act less prosocially and to be less helpful. These results extend previous findings on donation behavior by illustrating the importance of contextual factors in affecting psychological states related to "good will." Such simple differences as the

Table 3 Detailed descriptive statistics of field experiment across the three experiment conditions

\begin{tabular}{llllll}
\hline & $\begin{array}{c}\text { Total donation } \\
\text { converted to USD* }\end{array}$ & $\begin{array}{l}\text { Number of } \\
\text { visitors }\end{array}$ & $\begin{array}{c}\text { Number of } \\
\text { donations }\end{array}$ & $\begin{array}{c}\text { Average (per } \\
\text { donor) } \$\end{array}$ & $\begin{array}{c}\text { Number of } \\
\text { emails** }\end{array}$ \\
\hline $\begin{array}{l}\text { Opaque box } \\
\begin{array}{c}\text { Transparent box } \\
\text { (almost empty) }\end{array}\end{array}$ & 120.95 & 184 & 59 & 2.05 & 37 \\
$\begin{array}{c}\text { Transparent box } \\
\text { (almost full) }\end{array}$ & 72.15 & 201 & 33 & 1.78 & 14 \\
\hline
\end{tabular}

*The amounts were converted from Iranian Rial to US dollar to enable readers compare the means. The exchange rate is $1 \mathrm{USD}=32,000$ Rial

**In order to reduce the burden on assistants, they were instructed to approach every other student in a sequential manner for email collection. So a total of 289 students out of 578 were approached; 92 students from opaque box condition, 100 students from transparent almost-empty condition, and 97 students from transparent almost-full condition 
physical design of the donation box can exert a simple yet powerful effect on the decision to donate. These results carry a further evidentiary weight, in that they are among the first to study the relation between money priming and prosocial behavior in Middle Eastern countries; thus, they illustrate the generalizability of previous findings on money priming and self-sufficiency as influences on donation behavior.

There appears to be an important managerial implication from our findings. Our results indicate that opaque donation boxes, as opposed to transparent ones, might boost donations in contexts where the effects of money exposure on self-sufficiency may outweigh the focus on social normative information provided. In fact, one way of affecting donations is in the design and contents of the donation box itself. For example, Guèguen (2013) found that using donation boxes in the shape of animals, such as cats and dogs, significantly increased the donation amount. Importantly, numerous reports suggest that donations to charitable organizations have been decreasing continually over at least the last decade. For example, Charities Aid Foundation (2012) reported that globally since 2007, donations to charities experienced a noticeable decline; hence, by using opaque donation boxes, particularly in settings where individuals may be less prone to social influence, charities may increase their donation revenue. It may be possible, as well, to design donation boxes that provide social information regarding participation (to increase the norm of cooperation), without displaying actual money.

Although our results replicate across both lab and field studies, it is important to discuss limitations that future research might address. One limitation of the present research that may be studied in future was the fact that donation decisions were largely private and anonymous. A goal of the present research was to study the influence of box transparency on individual donation behavior and was designed to isolate the phenomenon from other factors (i.e., social pressure, social recognition). However, in many real-world situations, donation decisions are observable and thus may be subject to other factors such as social motives (i.e., tainted altruism; Lin-Healy and Small 2012, Newman and Cain 2014). Second, the charity used across all of studies was UNICEF. This may have reduced the generalizability of our findings for other charities; hence, future research may examine a wider type of charities and even treat the charity itself as one of the dependent variables. Third, the helping behavior-dependent variable measured and tested in the study 2 is binary, which makes it less sensitive. Lastly, future research may investigate whether and how our findings are affected by demographic characteristics of the donors.

\section{References}

Aaker, J. L., \& Akutsu, S. (2009). Why do people give? The role of identity in giving. Journal of Consumer Psychology, 19(3), 267-270.

Aknin, L. B., Barrington-Leigh, C. P., Dunn, E. W., Helliwell, J. F., Burns, J., Biswas Diener, R., \& Kemeza, I. (2013). Prosocial spending and well-being: cross-cultural evidence for a psychological universal. Journal of Personality and Social Psychology, 104, 635-652.

Anik, L., Norton, M. I., \& Ariely, D. (2014). Contingent match incentives increase donations. Journal of Marketing Research, 51(6), 790-801.

Caruso, E. M., Shapira, O., \& Landy, J. (2017). Show me the money: a systematic exploration of manipulations, moderators, and mechanisms of priming effects. Psychological Science, 28, 1148-1159. https://doi.org/10.1177/0956797617706161. 
Charitable Aid Foundation Report (2012). Available at https://www.cafonline.org/about-us/publications/2012publications/world-giving-index-2012, accessed on Nov 03. 2017.

Gasiorowska, A., \& Helka, A. (2012). Psychological consequences of money and money attitudes in dictator game. Polish Psychological Bulletin, 3(1), 20-26.

Guèguen, N. (2013). Redesigning the donation box: The effect of animal banks on donations for animal welfare. Society and Animals, 21(3), 240-248.

Guèguen, N., \& Jacob, C. (2013). Behavioral consequences of money: when the automated teller machine reduces helping behavior. The Journal of Socio-Economics, 47, 103-104.

Higgins, E. T., \& Brendl, C. M. (1995). Accessibility and applicability: some" activation rules" influencing judgment. Journal of Experimental Social Psychology, 31(3), 218-243.

Lea, S., \& Webley, P. (2006). Money as tool, money as drug: the biological psychology of a strong incentive. Behavioral and Brain Sciences, 29(02), 161-176.

Lin-Healy, F., \& Small, D. A. (2012). Cheapened altruism: discounting personally affected prosocial actors. Organizational Behavior and Human Decision Processes, 117(2), 269-274.

Meijer, M. (2009). The effects of charity reputation on charitable giving. Corporate Reputation Review, 12(1), 33-42.

Newman, G. E., \& Cain, D. M. (2014). Tainted altruism: when doing some good is evaluated as worse than doing no good at all. Psychological Science, 25(3), 648-655.

Schacter, D., \& Buckner, R. (1998). Priming and the brain. Neuron, 20(2), 185-195.

Tulving, E., \& Schacter, D. (1990). Priming and human memory systems. Science, 247(4940), 301-306.

Vohs, K. (2015). Money priming can change people's thoughts, feelings, motivations, and behaviors: an update on 10 years of experiments. Journal of Experimental Psycholgy: General, 144(4), e86-e93.

Vohs, K., Mead, N., \& Goode, M. (2006). The psychological consequences of money. Science, 314(5802), 1154-1156.

Vohs, K., Mead, N., \& Goode, M. (2008). Merely activating the concept of money changes personal and interpersonal behavior. Current Directions in Psychological Science, 17(3), 208-212.

Wang, C., Zhu, R. J., \& Handy, T. C. (2015). Experiencing haptic roughness promotes empathy. Journal of Consumer Psychology, 26(3), 350-362.

Whillans, A. V., Dunn, E. W., Sandstrom, G. M., Dickerson, S. S., \& Madden, K. M. (2016). Is spending money on others good for your heart? Health Psychology, 35(6), 574-583.

Zhou, X., Vohs, K., \& Baumeister, R. (2009). The symbolic power of money: reminders of money alter social distress and physical pain. Psychological Science, 20(6), 700-706. 